\title{
Is it compatible with breastfeeding? www.e-lactancia.org: Analysis of visits, user profile and most visited products
}

\author{
José María Paricio-Talayero ${ }^{\mathrm{a}}$, Desirée Mena-Tudela ${ }^{\mathrm{b}, *}$, Águeda Cervera-Gasch ${ }^{\mathrm{b}}$, \\ Víctor Manuel González-Chordá ${ }^{b}$, Yasmin Paricio-Burtin ${ }^{a}$, Marta Sánchez-Palomares ${ }^{a}$, \\ Nerea Casas-Maeso $^{\mathrm{a}, \mathrm{c}}$, Silvia Moyano-Pellicer ${ }^{\mathrm{a}}$, Konstantina Giannioti ${ }^{\mathrm{a}, \mathrm{c}}$, Alberto Heart ${ }^{\mathrm{a}}$, \\ Leonardo Landa-Rivera ${ }^{a}$
}

a Association for the Promotion of and Scientific and Cultural Research into Breastfeeding (APILAM), Spain
${ }^{\mathrm{b}}$ Department of Nursing. UniversitatJaume I. Castellón de la Plana, Spain

${ }^{\mathrm{c}}$ International Board Certified Lactation Consultant (IBCLC), Spain

\section{A R T I C L E I N F O}

\section{Keywords:}

Breast feeding

Pharmaceutical preparations

Information storage and retrieval

Product labelling

Drug labelling

Telemedicine

\begin{abstract}
A B S T R A C T
Introduction: One of the factors to influence abandoning breastfeeding is mothers' use of medications. The www. e-lactancia.org website is a reliable source in Spanish and English for online free-access information about the compatibility of medications with breastfeeding. The aim of this study was to analyse the search profiles, and groups and products, searched the most on this website.

Materials and methods: A retrospective and descriptive study of the e-lactancia.org website during 2014-2018. Google Analytics was used for data collection. The following variables were analysed: number of users and queries; professional profile; country; language; users' and groups' access modes/devices; most searched products.

Results: We found 16,821.559 users and 63,783.866 pages. Of users, $62.7 \%$ were "mother/father", and $31.9 \%$ were health professionals. Visits came mostly from: Spain (25.86 \%); Mexico (16.87 \%); Argentina (7.99 \%); Chile (7.31 \%). The preferred access mode and device were organic searches $(62.1 \%)$ and mobile phones (73.4 $\%)$, respectively. Phytotherapy (14.4\%), antibacterial agents $(12.3 \%)$ and NSAIDs (12.3\%) were the most searched groups, and ibuprofen (6.25 \%) was the most popular product.

Conclusion: Users and consultations in e-lactation increased significantly during the study period. Mothers/fathers were the main website users, followed by health professionals. The main consulted groups were antibacterial agents, NSAIDs and systemic phytotherapy. Ibuprofen, paracetamol and amoxicillin stood out as the most consulted products. These results revealed increase Internet resources use to solve parents and health professionals' breastfeeding doubts. Future research should study how users (parents, health professionals) interact with this information.
\end{abstract}

\section{Introduction}

Non-compliance with the current World Health Organization (WHO) recommendations on breastfeeding (BF), as fewer than $40 \%$ of infants younger than 6 months old exclusively receive breast milk as food [1], poses a health risk for mothers and infants due to the innumerable benefits of breast milk as a protective factor against various infections [2], cancers [3] and other diseases [4] in newborns and infants. Regarding maternal health, BF promotes weight loss after childbirth [5], prolongs amenorrhea and reduces risks of breast and ovarian cancer, type 2 diabetes and cardiovascular disease [6]. BF improves the health of mothers and babies worldwide [7].

Of the different factors that influence abandoning $\mathrm{BF}$ are use of pacifiers [8], providing water to infants [9], the maternal perception of low milk production, increasing infants' low birth weight, maternal selfefficacy levels $[10,11]$ and mothers using medications [12-15]. Many women take medications during BF [13,14], and up to $23 \%$ of early lactation interruptions are directly or indirectly associated with their use [15-17].

Computer science, new technologies, physiological processes and daily life currently overlap to the extent that there is constant healthrelated information and learning sites on every website part. BF has not

\footnotetext{
* Corresponding author at: Department of Nursing, Faculty of Health Sciences, University Jaume I, Avda. Sos I Baynat s/n 12071, Castellón de la Plana, Spain.

E-mail address: dmena@uji.es (D. Mena-Tudela).
} 
escaped this condition as many mothers seek information about BF for their babies on the website [18].

The Global Digital Report 2018 [19] revealed that more than 4 billion people worldwide use the Internet; i.e., more than half of the world's population is online, and almost 250 million new users were connected for the first time in 2017. The use of social media continues to grow rapidly. Mmore than 3 billion people use it every month, and 9 in every 10 users employ mobile devices. As noted by Andrew Arnold, "Parents have always sought out advice from others. Some generations looked to their parents and grandparents. Others relied on books from experts like Benjamin Spock. Today, $71 \%$ of millennials value the advice and insights they receive from parenting blogs, parenting web sites, forums, and social networks" [20].

Therefore, the combination of new technologies and social media can influence BF rates. Health professionals also seek information on the website, whose main common reason for using and retrieving information online is to bridge a knowledge gap [21,22].

In this article, the e-Health counselling tool www.e-lactancia.org was studied based on health products with $\mathrm{BF}$ in order to analyse the search profiles and groups and products that are most searched on this website.

\section{Materials and methods}

A retrospective, comparative and descriptive study was conducted of the data recorded by the e-Health e-lactancia.org tool from 01.01.2014 to 31.12.2018 (5 full years).

This tool was conceived due to the dispersion of information on $\mathrm{BF}$ compatibility with taking drugs and medicinal plants, exposure to environmental pollutants or maternal diseases. It was created in 2000 in the Paediatric Service of a hospital that had obtained the UNICEF Baby Friendly Initiative accreditation in 1999 as a small database for using the service. For convenience purposes, it was uploaded to the Internet in 2002 and has grown since then with 1866 different products belonging to 192 groups, 8332 synonyms and 17,698 commercial brands (from the Martindale list), although the database is linked with active ingredients. e-lactancia.org contains 28,088 index terms.

The e-lactancia.org website has been recognised by prestigious organisations like the Academy of Breastfeeding Medicine, which has recommended it in several of its articles and protocols [23,24], La Leche League, iHan, the Grecia-Institute of Child's Health in Greece, the National Confederation of Pediatrics (Confederación Nacional de Pediatría - CONAPEME) and the Breastfeeding Association (Asociación Pro Lactancia Materna - APROLAM) in Mexico.

The e-lactancia.org website is composed of a search engine with which the inquiring person can input the term with which (s)he intends to assess compatibility with BF. The database returns a response, including an explanatory comment and some pharmacokinetic data, both based on the scientific literature, which are periodically updated and reviewed in each researched product, disease or medication. In addition, the response classifies the risk and compatibility of BF in relation to the searched product with the following easily interpretable colourcode.

- Green-Very low risk: safe product, compatible with BF with sufficient information published in the scientific literature or with more than one of the following characteristics: lack of demonstrated toxicity; frequent use in neonates or small infants with no side effects; extensive regular or traditional consumption; very favourable pharmacokinetics; consensus of experts.

- Amber-Low risk: quite safe and most likely compatible. Its use could have very mild adverse effects on BF or lactation. The physicochemical and pharmacokinetic characteristics of product absorption, distribution and elimination mean that the appearance of adverse effects is very unlikely; such data have either been reported or do not exist.
- Orange-High risk: unsafe, difficult compatibility. Evaluate carefully. Use a safer alternative or interrupt BF for several $\mathrm{T}^{1 / 2}$ periods (elimination half-life). Products considered high risk are those that could have moderate or severe adverse effects on BF or lactation. The physico-chemical and pharmacokinetic characteristics of product absorption, distribution and elimination mean that the appearance of adverse effects is very unlikely; such data have either been reported or do not exist.

- Red-Very high risk: very unsafe. Contraindicated. Use an alternative or cease BF. The $\mathrm{T}^{1 / 2}$ of the drug is too long to consider temporary $\mathrm{BF}$ interruption an alternative. Due to published data or the characteristics of the substance, a high probability of it being toxic to the infant or detrimental to lactation by inhibiting it is known or assumed.

Each product can be searched directly by either its name or the group to which it belongs, or by its trademark, a synonym and other names in other scripts. When the product presents a high or a very high risk, possible alternatives that are more compatible with BF (if any) are presented through the same search. e-lactancia.org is regularly updated by the APILAM group (Association for the Promotion and Scientific and Cultural Research of Breastfeeding), a non-profit association. This website is supported mainly by voluntary donations from mothers, healthcare providers and breastfeeding support groups, and also by teaming groups. APILAM is formed by four paediatricians, three pharmacists and one nurse. It updates the database in several ways: when a new alert is received from a database (mainly PubMed); when a user writes to propose an update; systematically when the 100 most visited products are updated.

\subsection{Data collection and analysis}

The Google Analytics tool was used for data collection. This tool does not contain any personal data or confidential information, and comes as aggregated data [25]. Among the variables that can be collected through Google Analytics, and which were analysed globally and disaggregated by year, we find: number of users, numbers of accesses and queries, access languages, subcontinents and countries from which access occurs, type of electronic device through which access is gained (computer, tablet, mobile), professional user profile. Moreover, there are sources of origin of the search and products about which user is informed on the website: drugs, therapeutic groups, phytotherapy and alternative products, contaminants and diseases. The level of risk assigned in e-lactancia.org was added to each analysed product.

A descriptive analysis was performed for all the variables using absolute and relative frequencies expressed as percentages. The pairwise differences in years were calculated for devices and access channels by the chi-square test.

\section{Results}

Table 1 shows how the number of users of e-lactancia.org increased year by year between 2014 and 2018, and went from 1.13 million in 2014 to 6.18 million in 2018 . The numbers of sessions and page views also rose. The total number of users during the study period (2014-2018) was 16.8 million, with 63.8 million page views.

The subcontinents from which more web visits came were Central America (+ Mexico) (26.43\%), South America (24.62 \%) and southern Europe (18.99 \%) (Fig. 1). The most prominent countries were Spain (25.86\%), Mexico (16.87\%), Argentina (7.99\%), Chile (7.31\%), Colombia (5.43 \%), Peru (3.27\%), the United States (2.82 \%), Russia (2.64 \%) and Portugal (1.94\%).

The main language used by access devices was Spanish (76 \%), followed by English (8.5 \%), Portuguese (4.2\%) and Russian (4\%).

The access channels to e-lactancia.org were through "organic" searches (not paid) on search engines (62.1\%), by direct URLs (23.8 
Table 1

Numbers of users, sessions and pages and average pages per session visited by users of e-lactancia.org during the study period (2014-2018).

\begin{tabular}{lllll}
\hline Year & Users & Sessions & Pages & Pages/Session \\
\hline 2014 & $1,127,540$ & $1,741,230$ & $6,073,393$ & 3.49 \\
2015 & $1,943,901$ & $3,093,853$ & $9,278,509$ & 3.00 \\
2016 & $3,035,356$ & $4,623,224$ & $11,641,765$ & 2.52 \\
2017 & $4,532,746$ & $6,800,107$ & $16,580,344$ & 2.44 \\
2018 & $6,182,016$ & $9,471,137$ & $20,209,855$ & 2.13 \\
Total & $16,821,559$ & $25,729,551$ & $63,783,866$ & 2.48 \\
\hline
\end{tabular}

$\%$ ), from social networks ( $8.2 \%)$ and through links from other websites (5.8\%), with mobile phones (73.4\%) as the most widely used access device, followed by personal computers $(22.6 \%)$ and tablets $(4.0 \%)$. Tables 2 and 3 show the annual increases between 2014 and 2018 of mobile phones as an access device to e-lactancia.org and of "organic" searches as an access channel, respectively. Statistically significant differences were found between all the pairs of years analysed by devices and access channels $(\mathrm{p}<0.05)$.

The most frequently found professional profile $(25.1 \%$ declared $)$ was "mother/father" (62.7 \%), followed by "health professionals" (31.9 $\%$, including $8 \%$ paediatricians, $5.3 \%$ nurses and $3.4 \%$ midwives) and "consultants/support groups" (3.16 \%).

Product queries on the website came to $30,623,967$. Table 4 shows the numbers and percentages of the most researched groups.

Among the most searched products per group, the following stood out (percentages of the total number of visits): antibacterial agents, amoxicillin (2.3\%); NSAIDs, ibuprofen (6.25\%); phytotherapy, fennel (0.85\%); analgesics, paracetamol (2.77\%); antihistamines, loratadine (1.73\%); diet supplements, coffee (0.64\%); maternal diseases, urinary infection (0.23\%); maternal activities, tattooing (0.65\%); anti-ulcer
Table 2

Access channels to e-lactancia.org used by users during 2014-2018. Number and percentage of total annual access and total.

\begin{tabular}{|c|c|c|c|c|c|c|c|c|}
\hline \multirow[t]{2}{*}{ Year } & \multicolumn{2}{|c|}{ Organic search } & \multicolumn{2}{|l|}{ Direct } & \multicolumn{2}{|l|}{ Social } & \multicolumn{2}{|l|}{ Referral } \\
\hline & $\mathrm{N}$ & $\%$ & $\mathrm{~N}$ & $\%$ & $\mathrm{~N}$ & $\%$ & $\mathrm{~N}$ & $\%$ \\
\hline 2014 & 448,776 & 46.8 & 287,548 & 30.0 & 74,213 & 7.7 & 148,207 & 15.5 \\
\hline 2015 & 938,237 & 56.6 & 412,430 & 24.9 & 140,100 & 8.4 & 167,763 & 10.1 \\
\hline 2016 & $1,448,644$ & 57.2 & 647,239 & 25.6 & 222,597 & 8.8 & 211,729 & 8.4 \\
\hline 2017 & $2,309,335$ & 64.0 & 831,459 & 23.0 & 319,108 & 8.9 & 147,994 & 4.1 \\
\hline 2018 & $3,237,721$ & 68.5 & $1,047,649$ & 22.2 & 335,782 & 7.1 & 102,605 & 2.2 \\
\hline Total & $8,382,713$ & 62.2 & $3,226,325$ & 23.9 & $1,091,800$ & 8.1 & 778,298 & 5.8 \\
\hline
\end{tabular}

Organic Search: Traffic from unpaid search on any search engine; Direct: Sessions during which the user typed the name of your website URL into the browser or came to your site via a bookmark; Social: Traffic from any of approximately 400 social networks (not tagged as ads); Referral: Traffic from websites that are not social networks.

medicines, omeprazole (1\%); drugs of abuse, alcohol (1.38\%); contraceptives, levonorgestrel (0.54\%); anxiolytics, diazepam (0.48\%); decongestants, phenylephrine $(0.61 \%)$; antidepressants, sertraline $(0.42 \%)$. Tables $5 \mathrm{a}$ and $5 \mathrm{~b}$ shows the 75 most searched products, which accounted for $50 \%$ of the total number of queries during the study period. This table also includes a column with the risk level assigned on the e-lactancia.org website.

\section{Discussion}

The e-lactancia.org tool very significantly increased as far as users are concerned from year to year: the number of visits increased 10-fold from 2014 to 2018.

One of the factors to explain these millions of annual visits to e-

\section{Western Europe}

\section{$2 \%$}

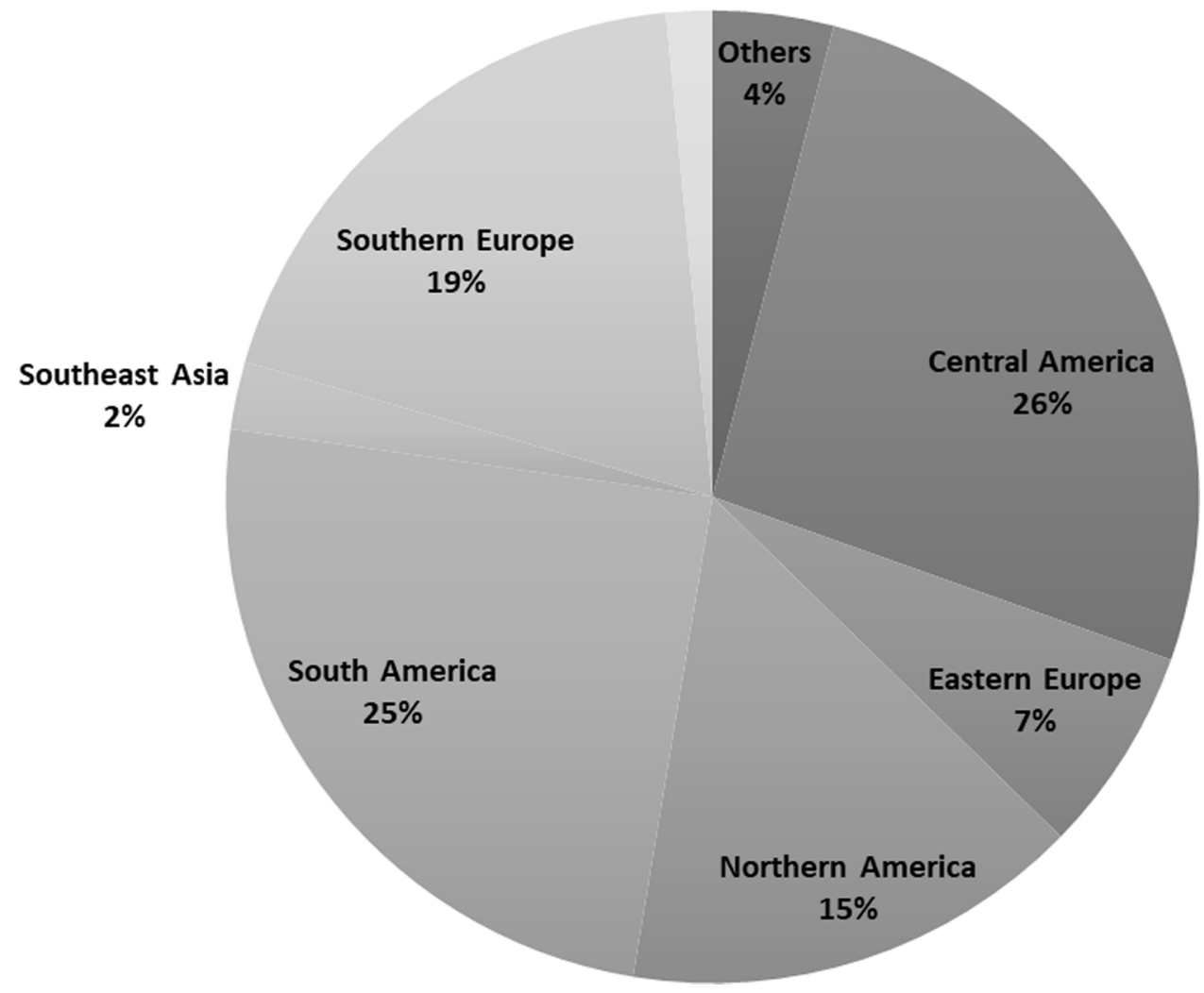

Fig. 1. Visits to www.e-lactancia.org by subcontinents. 
Table 3

Type of device used to access e-lactancia.org during (2014-2018), $\mathrm{n}$ and (\%).

\begin{tabular}{|c|c|c|c|c|c|c|c|c|}
\hline \multirow[t]{2}{*}{ Year } & \multicolumn{2}{|l|}{ Mobile } & \multicolumn{2}{|l|}{ Desktop } & \multicolumn{2}{|l|}{ Tablet } & \multicolumn{2}{|l|}{ Total } \\
\hline & $\mathrm{n}$ & $\%$ & $\mathrm{n}$ & $\%$ & $\mathrm{n}$ & $\%$ & $\mathrm{n}$ & $\%$ \\
\hline 2014 & 413,880 & 46.5 & 388,501 & 43.6 & 88,590 & 9.9 & 890,971 & 100.0 \\
\hline 2015 & 960,680 & 61.1 & 493,314 & 31.4 & 117,874 & 7.5 & $1,571,868$ & 100.0 \\
\hline 2016 & $1,732,401$ & 72.2 & 547,969 & 22.9 & 117,473 & 4.9 & $2,397,843$ & 100.0 \\
\hline 2017 & $2,659,552$ & 77.1 & 679,215 & 19.7 & 109,706 & 3.2 & $3,448,473$ & 100.0 \\
\hline 2018 & $3,704,604$ & 81.1 & 770,963 & 16.9 & 92,520 & 2.0 & $4,568,087$ & 100.0 \\
\hline Total & $9,038,072$ & 73.4 & $2,783,090$ & 22.6 & 494,835 & 4.0 & $12,315,997$ & 100.0 \\
\hline
\end{tabular}

Table 4

Number of searches grouped as therapeutic group and percentage of total $(30,623,967)$ searches on e-lactatancia.org products during 2014-2018.

\begin{tabular}{lll}
\hline \multirow{2}{*}{ Groups } & \multicolumn{2}{l}{ Search } \\
\cline { 2 - 3 } & $\mathrm{A}$ & $\%$ \\
\hline Antibacterial agents & $3,761,124$ & 12.28 \\
NSAIDs & $3,757,563$ & 12.27 \\
Systemic phytotherapy & $3,377,574$ & 11.03 \\
Analgesics & $1,721,999$ & 5.62 \\
Antihistamines & $1,705,804$ & 5.57 \\
Diet supplements & $1,258,784$ & 4.11 \\
Topical phytotherapy & $1,042,251$ & 3.40 \\
Maternal disease & 762,402 & 2.49 \\
Maternal activities (sports, cosmetic, sanitary, etc.) & 702,484 & 2.29 \\
Anti-acid reflux & 6558,001 & 2.15 \\
Drug abuse & 649,172 & 2.12 \\
Contraceptives & 592,223 & 1.93 \\
Anxiolytics, hypnotics and sedatives & 545,925 & 1.78 \\
Decongestants & 532,838 & 1.74 \\
Antidepressants & 460,181 & 1.50 \\
\hline
\end{tabular}

NSAIDs: non-steroidal anti-inflammatory agents.

lactancia.org is lack of scientific information in the lactation section of the brochures and fact sheets prepared by the pharmaceutical industry for its products [26,27]. A short phrase very often indicates that the drug is contraindicated during $\mathrm{BF}$ (or BF "should be discontinued while taking medication", which completely ignores how complicated it can be to interrupt and resume $\mathrm{BF}$, and disregards the proven benefits of $\mathrm{BF}$ for mothers and infants). No evidence for this claim is offered or, at the most, it states that medication can pass to breast milk, or in animals (generally rats), it has been detected in breast milk. Nor do they report the amount excreted or the possible or proven problems for either infants or BF. This biased legal-defensive information [26] in prospectuses has conditioned medical professionals to systematically deny the compatibility of $\mathrm{BF}$ with taking any medication despite the paucity of according evidence because few or no reactions observed in infants can be definitively attributed to nursing mothers taking medications [15].

With the advent of the information society, and the rise in and importance attached to BF at the start of in the 1990s, this model of absolute incompatibility between BF and medications, and the work of pioneering specialists like Briggs (Drugs in Pregnancy and Lactation, 1983), Dr. Bennet (Drugs and Human Lactation, 1988) and Dr. Hale (Medications and Mother's Milk, 1992), reached professionals and the general public. The creation of the LactMed website (https://toxnet. nlm.nih.gov/newtoxnet/lactmed.htm) in 2003 by Dr. P.O. Anderson contributed to this change [28].

The fact that e-lactancia.org is a free-access Internet database based on scientific and up-to-date data, and one that is easy and intuitive managed, allowed us to quickly obtain accurate information, which explains the very large number of queries.

The number of health professionals concerned about maintaining BF is increasing, and they should have accurate information about the
Table 5a

Most visited products, 2014-2018 (5 years), number of searches and percentage of all $(30,623,967)$ the product searches. Level of risk assigned in e-lactancia.

\begin{tabular}{|c|c|c|c|c|}
\hline & Product name & No. of visits & $\%$ & e-lactancia risk \\
\hline 1 & Ibuprofen & $1,913,392$ & 6.25 & 0 \\
\hline 2 & Paracetamol & 848,758 & 2.77 & 0 \\
\hline 3 & Amoxicillin & 702,820 & 2.30 & 0 \\
\hline 4 & Loratadine & 530,239 & 1.73 & 0 \\
\hline 5 & Diclofenac & 519,635 & 1.70 & 0 \\
\hline 6 & Alcohol (drinks) & 420,894 & 1.37 & 2 \\
\hline 7 & Amoxicillin-clavulanic acid & 328,487 & 1.07 & 0 \\
\hline 8 & Chlorphenamine & 322,721 & 1.05 & 1 \\
\hline 9 & Ciprofloxacin & 314,572 & 1.03 & 0 \\
\hline 10 & Omeprazole & 308,083 & 1.01 & 0 \\
\hline 11 & Naproxen & 307,077 & 1.00 & 1 \\
\hline 12 & Cetirizine hydrochloride & 276,172 & 0.90 & 0 \\
\hline 13 & Metoclopramide & 272,303 & 0.89 & 0 \\
\hline 14 & Ketorolac-trometamol & 263,121 & 0.86 & 0 \\
\hline 15 & Fennel & 261,202 & 0.85 & 2 \\
\hline 16 & Ginger & 251,897 & 0.82 & 0 \\
\hline 17 & Azithromycin & 244,659 & 0.80 & 0 \\
\hline 18 & Metronidazole & 232,796 & 0.76 & 0 \\
\hline 19 & Metamizole & 214,585 & 0.70 & 1 \\
\hline 20 & Chamomile & 208,983 & 0.68 & 0 \\
\hline 21 & Cephalexin & 208,605 & 0.68 & 0 \\
\hline 22 & Tattoo & 199,657 & 0.65 & 1 \\
\hline 23 & Coffee & 195,870 & 0.64 & 1 \\
\hline 24 & Phenylephrine & 186,543 & 0.61 & 1 \\
\hline 25 & Aspirin & 185,630 & 0.61 & 1 \\
\hline 26 & Dexamethasone & 172,378 & 0.56 & 1 \\
\hline 27 & Levonorgestrel & 165,360 & 0.54 & 0 \\
\hline 28 & Ranitidine & 160,014 & 0.52 & 0 \\
\hline 29 & Acetylcysteine & 159,442 & 0.52 & 0 \\
\hline 30 & Ambroxol & 152,246 & 0.50 & 0 \\
\hline 31 & Diazepam & 147,454 & 0.48 & 1 \\
\hline 32 & Dextromethorphan & 146,980 & 0.48 & 0 \\
\hline 33 & Domperidone & 143,948 & 0.47 & 0 \\
\hline 34 & Clindamycin & 143,900 & 0.47 & 1 \\
\hline 35 & Tramadol & 139,083 & 0.45 & 0 \\
\hline 36 & Local anesthesia & 137,887 & 0.45 & 0 \\
\hline 37 & Clotrimazole & 135,267 & 0.44 & 0 \\
\hline 38 & Fluconazole & 134,980 & 0.44 & 0 \\
\hline 39 & Pennyroyal & 134,641 & 0.44 & 2 \\
\hline 40 & Ampicillin & 133,520 & 0.44 & 0 \\
\hline
\end{tabular}

compatibility of medications and BF to advise them in their decision making [26,27]. The e-lactancia.org website offers a clear advantage: as it is a digital tool, it allows rapid information dissemination and data can be updated in real time, as highlighted in some articles $[29,30]$. It also helps to avoid the main barrier detected in using online information, especially in the primary healthcare field: lack of time [31].

Although the e-lactancia.org website is designed to help professionals, the concise style of its comments and its intuitive way of showing the risk level on a traffic light scale have led to mothers themselves being its most frequent users for years, who account for almost two thirds of visits. The e-lactancia.org website allows BF mothers' active participation in clinical decisions that can affect BF, which can end in the decision to abandon it [30,32], and limit mothers' 
Table 5b

Most visited products, 2014-2018 (5 years). Number of visits and percentage of the total.

\begin{tabular}{|c|c|c|c|c|}
\hline & Product name & No. of visits & $\%$ & $\begin{array}{l}\text { e-lactancia risk } \\
*\end{array}$ \\
\hline 41 & Acyclovir & 128,890 & 0.42 & 0 \\
\hline 42 & Betamethasone & 128,274 & 0.42 & 1 \\
\hline 43 & Sertraline hydrochloride & 127,857 & 0.42 & 0 \\
\hline 44 & Pseudoephedrine & 125,383 & 0.41 & 1 \\
\hline 45 & Caffeine & 124,715 & 0.41 & 1 \\
\hline 46 & Metformin hydrochloride & 124,210 & 0.41 & 0 \\
\hline 47 & Ketoprofen & 124,152 & 0.41 & 0 \\
\hline 48 & Anise & 123,712 & 0.40 & 1 \\
\hline 49 & Desloratadine & 122,753 & 0.40 & 0 \\
\hline 50 & Prednisone & 121,189 & 0.40 & 0 \\
\hline 51 & Lorazepam & 120,102 & 0.39 & 0 \\
\hline 52 & Lidocaine & 117,327 & 0.38 & 0 \\
\hline 53 & Sodium bicarbonate & 114,242 & 0.37 & 0 \\
\hline 54 & Nimesulide & 111,798 & 0.37 & 2 \\
\hline 55 & Valerian & 107,671 & 0.35 & 1 \\
\hline 56 & Tobacco & 106,872 & 0.35 & 2 \\
\hline 57 & Ceftriaxone sodium & 105,962 & 0.35 & 0 \\
\hline 58 & Clonazepam & 101,787 & 0.33 & 1 \\
\hline 69 & Loperamide hydrochloride & 101,492 & 0.33 & 0 \\
\hline 60 & Cinnamon & 101,089 & 0.33 & 0 \\
\hline 61 & Sulpiride & 95,178 & 0.31 & 0 \\
\hline 62 & Codeine & 93,549 & 0.31 & 2 \\
\hline 63 & Tea & 91,588 & 0.30 & 1 \\
\hline 64 & Cocaine & 88,913 & 0.29 & 3 \\
\hline 65 & $\begin{array}{l}\text { Levonorgestrel (3-day } \\
\text { contraceptive) }\end{array}$ & 86,868 & 0.28 & 0 \\
\hline 66 & Star anise & 85,344 & 0.28 & 3 \\
\hline 67 & Clarithromycin & 85,331 & 0.28 & 0 \\
\hline 68 & Nitrofurantoin & 84,849 & 0.28 & 0 \\
\hline 69 & $\begin{array}{l}\text { Sulphamethoxazole and } \\
\text { trimethoprim }\end{array}$ & 84,537 & 0.28 & 0 \\
\hline 70 & Levofloxacin & 83,058 & 0.27 & 1 \\
\hline 71 & Linden & 82,981 & 0.27 & 0 \\
\hline 72 & Mint & 81,009 & 0.27 & 0 \\
\hline 73 & Hair dyes & 80,614 & 0.26 & 1 \\
\hline 74 & Beer yeast & 80,570 & 0.26 & 0 \\
\hline 75 & Yerba mate & 80,018 & 0.26 & 0 \\
\hline
\end{tabular}

* Level of risk assigned in e-lactancia: 0: Very low (green), 1: low (amber), 2: high (orange), 3: very high (red).

perception that the medication, if necessary, can be harmful during $\mathrm{BF}$ [33].

Conversely in most countries, the usual ratio between the number of mothers and that of professionals rarely exceeds 10 doctors and 10 nurses per thousand inhabitants [34]; that is, less than $2 \%$ on the whole, and $32 \%$ of users are health professionals. These proportions indicate the trust and usefulness that physicians, nurses, midwives, pharmacists and other health professionals place in e-lactancia.org.

The fact that Spanish-speaking countries are the source of most visits and Spanish is the most widely used language for access devices are explained by the origin of the site's creation. Nevertheless, it has reached other countries, such as the United States and Russia, and is accessed in languages like English, Portuguese and Russian [35].

Despite e-lactancia.org not having as an application (app) intended for tablets or smartphones, the responsive or adaptive web design of elactancia.org since 2013 has led to most accesses occurring via mobile phones rather than personal computers and tablets, which falls in line with Internet users' current trends [35].

In 5 years, 63.8 million entries to the e-lactancia.org website were counted, of which slightly less than half (30.6 million) were product visits (medications, plants, diseases, others) because most users enter elactancia.org through the landing page to search for a desired product. There are also several pages on e-lactancia.org that are not productrelated, like a page to make donations, a page for sponsors, a page for endorsements, the "About us" page and a page for statistics, which users also visit.

The most searched products on the e-lactancia.org tool reflect, among professionals, both the most prescribed and those that suggest doubts about compatibility with BF. Among mothers, the most consumed are those related to their concerns about the compatibility of their use during lactation [16]. These patterns are distributed similarly to that indicated in other studies [14].

As adequate accessible information is lacking, professionals often recommend mothers interrupting $\mathrm{BF}[13,16]$, although few products are absolutely contraindicated $[15,32,36]$. Hence it would be appropriate to make a risk assessment and search before making a decision $[13,37]$.

The most searched groups of drugs were antibacterial and nonsteroidal anti-inflammatory drugs (NSAIDs), with more than 3.7 million visits each, followed by analgesics and antihistamines (1.7 million views each). However, when we added systemic and topical phytotherapy products together, phytotherapy was the most searched product group, with 4.8 million visits in all, which reflects the high level of approval of these products by nursing mothers and some professionals [38]. The authors of e-lactancia.org emphasise that bibliographic references on phytotherapy products and lactation are often missing, which would make an adequate risk assessment difficult.

Of the 1866 products referenced in e-lactancia.org, only 75 account for $50 \%$ of total visits, with ibuprofen at the top (1.9 million visits), followed in this order by: paracetamol, amoxicillin, loratadine and diclofenac (with more than half a million visits each). It is noteworthy that the sixth most searched product is alcohol, which reflects mothers' concern about the effects that alcohol consumption may have on BF or their infant. In addition to discouraging it, it is advisable to well report the waiting times for $\mathrm{BF}$ and to avoid co-sleeping after drinking because approximately half western $\mathrm{BF}$ mothers consume alcohol during $\mathrm{BF}$ [39]. Of these 75 most visited products, only two, star anise and cocaine, are classified on e-lactancia.org as a very high risk, six are classified as high risk, and the remainder as low or very low risk.

On 30 June, 2015, the Food and Drug Administration (FDA) of the United States published new recommendations on the labelling of drugs and products: the Pregnancy and Lactation Labeling Rule (PLLR) $[30,40]$. This forced a change in the subsection entitled "Nursing Mothers" to "Lactation", which should be divided into three sections: Risk Summary, a summary of drug absorption; concentration in milk; the actual or estimated daily dose for infants; the effect of the drug on milk production; a risk/benefit statement; Clinical considerations, which describes recommendations about how to minimise exposure to a drug and how to control undesirable side effects; Data Section, which should include all the available studies supporting the summary of risk assessments. In addition, whenever there data are available for humans, no animal data should be included [30,40]. e-lactancia.org complies with these FDA requirements, which have gradually been implemented until 2020. Furthermore, e-lactancia.org includes the following: product name, synonyms, chemical formula; the Anatomical, Therapeutic, Chemical Classification System (ATC); date of the last update of the last searched product or medication; if there has been any change in the risk level; a comment with data on absorption and excretion in breast milk; estimated dose for infants; possible effects on infants or lactation; assigning the risk level on a colour-coded scale (green: very low risk; amber: low risk; orange: high risk; red: very high risk); possible safer alternatives, as shown in Fig. 2; pharmacokinetics data; the list of references consulted to make recommendations (none of these should be accompanied by animal data); finally, a list of trademarks.

\section{Conclusion}

The number of users and consultations in e-lactation significantly increased during the study period. Mothers and fathers were the main website users, followed by health professionals. The main consulted 


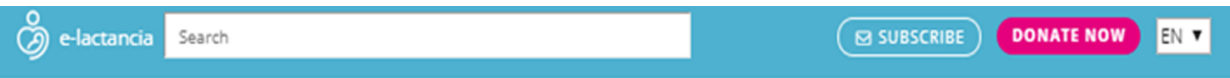

Last update: May 1, 2019

\section{Metamizole}
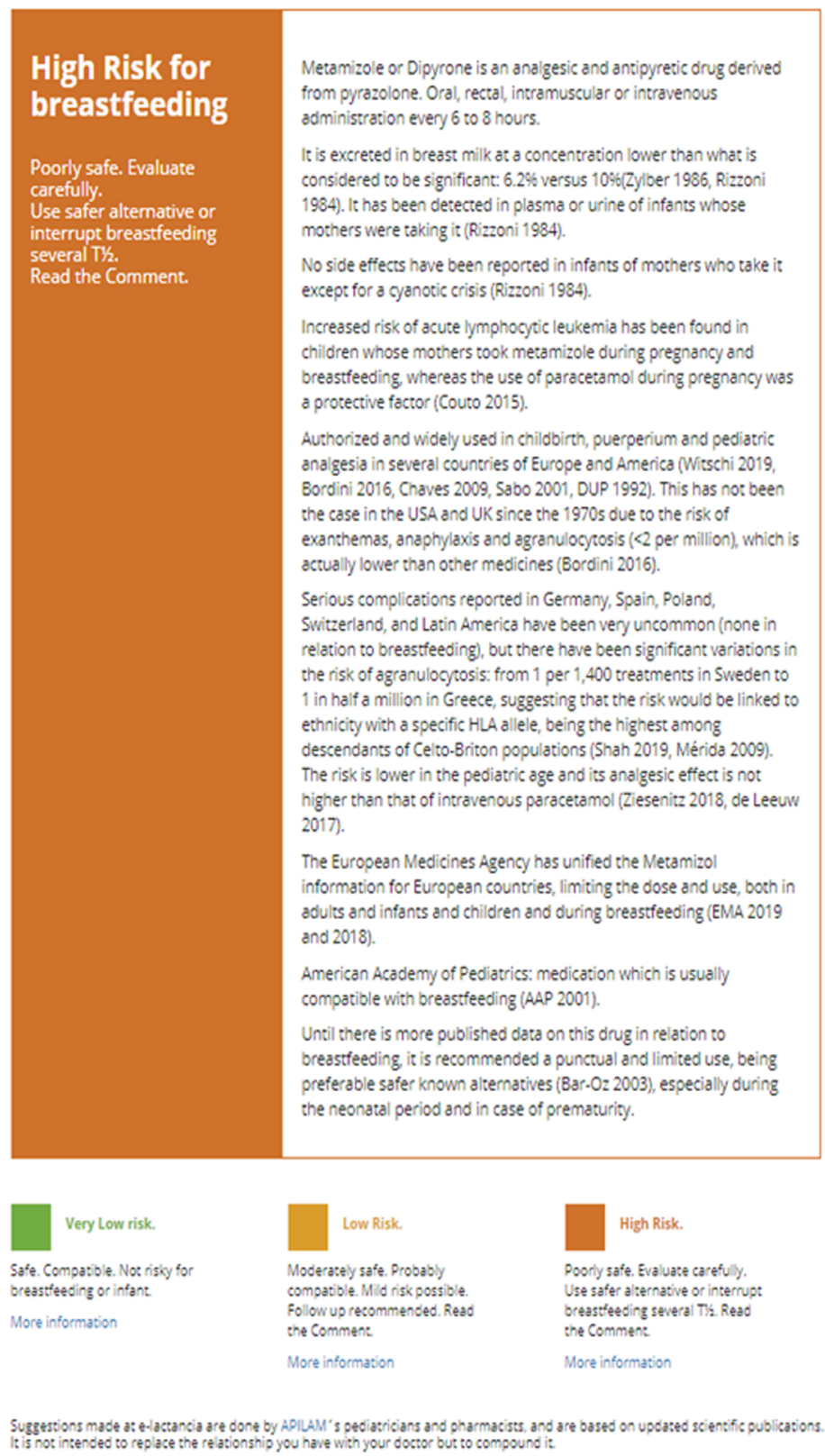

It is excreted in breast milk at a concentration lower than what is

1984) it has been derected in plasma or urine of infants whose mothers were taking it (Rizzoni 1984).

No side effects have been reported in infants of mothers who take i:

Increased risk of acute lymphocytic leukemia has been found in children whose mothers took metamizole during pregnancy and breastfeeding, whereas the use of paracetamol during pregnancy was

Authorized and widely used in childbirth, puerperium and pediatric ana'gesia in several countries of Europe and America (Witschi 2019, the case in the USA and UK since the 1970 s due to the risk of exanthemas, anaphylaxis and agranulocycosis ( $<2$ per million), which is actually lower than other medicines (Bordini 2016).

Serious complications reported in Germany, Spain, Poland, Switzerland, and Latin America have been very uncommon (none in reation to breastfeeding), but there have been significant variations in the rsk of agranulocycos s: from 1 per 1,400 treatments in Sweden to ethnicity with a specific HLA allele, being the highest among descendants of Cel to-Briton populations (Shah 2019, Mérida 2009). The risk is lower in the pediatric age and its analgesic effect is not higher than that of intravenous paracetamol (Ziesenitz 2018, de Leeuw information for European countries, limiting the dose and use, both in adults and infants and children and during breastfeeding (EMA 2019 and 2018). preferable safer known alternatives (Bar.Oz 2003) especially during the neonatal period and in case of prematurity.

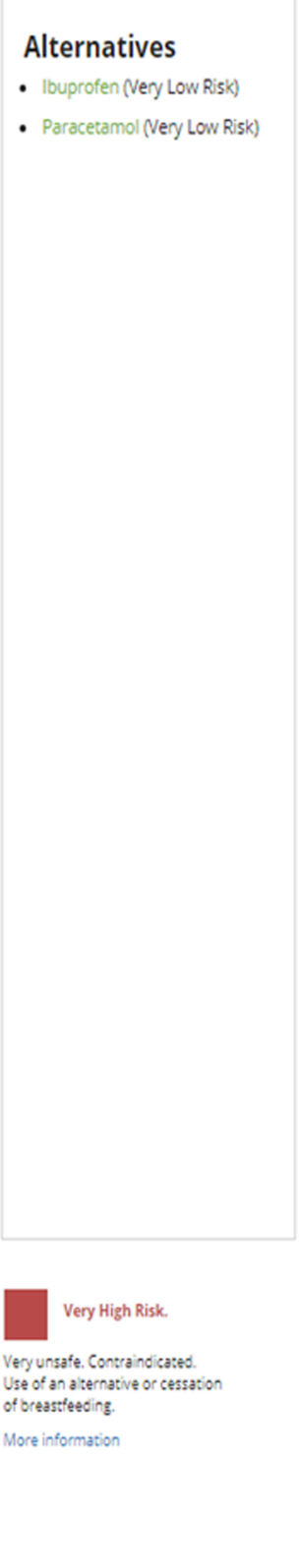

\section{Alternatives}

- Ibuprofen (Very Low Risk)

- Paracetamol (Very Low Risk)

Fig. 2. Example of the data shown when consulting a product at www.e-lactancia.org. groups were antibacterial agents, NSAIDs and systemic phytotherapy. The main consulted products that sttod out were ibuprofen, paracetamol and amoxicillin.

These results are very interesting because they reveal an increased use of this web resource, and probably other similar ones, to solve doubts about the compatibility of drugs and other substances with BF. In addition, determining the main consulted groups and products opens up work lines in order to, for example, improve health professionals' education and to attract those parents interested in BF. Future research about how users (parents and health professionals) interact with this information should be conducted.

\section{Summary table}

- We provide relevant data about visits, user profiles and most visited products on the www.e-lactancia.org website

- We observed how this website was increasingly accepted given its compatibility with breastfeeding

- The increased visits by health professionals was noteworthy and in accordance with technological evolution as websites 
can now be accessed with mobile phones

- It has been shown as a tool for determining the compatibility of many products with breastfeeding, it is scientifically endorsed and it complies with Food and Drug Administration recommendations

\section{Author statement}

The details of authorship of this work are as follows.

José María Paricio-Talayero and Desirée Mena-Tudela conceived and designed the study.

Yasmin Paricio-Burtin and Desirée Mena-Tudela collected the data and worked on the database.

Desirée Mena-Tudela and José María Paricio-Talayero analyzed and interpreted the data and wrote the article.

Águeda Cervera-Gasch; Víctor Manuel González-Chordá; Marta Sánchez-Palomares; Nerea Casas-Maeso; Leonardo Landa-Rivera; Silvia Moyano-Pellicer, Konstatnina Giannioti and Alberto Heart supervised the whole process and reviewed the article, with important intellectual contributions.

The final version of the article was approved by the entire team.

\section{Declaration of Competing Interest}

None.

\section{References}

[1] World Health Organization. 10 Facts on Breastfeeding, (2019) Published 2017. Accessed July 15 https://www.who.int/features/factfiles/breastfeeding/en/.

[2] M.A. Quigley, C. Carson, A. Sacker, Y. Kelly, Exclusive breastfeeding duration and infant infection, Eur. J. Clin. Nutr. 70 (12) (2016) 1420-1427, https://doi.org/10. 1038/ejcn.2016.135.

[3] R.M. Martin, D. Gunnell, C.G. Owen, G.D. Smith, Breast-feeding and childhood cancer: a systematic review with metaanalysis, Int. J. Cancer 117 (6) (2005) 1020-1031, https://doi.org/10.1002/ijc.21274.

[4] P.F. Pereira, R.D.C.G. Alfenas, R.M.A. Araújo, Does breastfeeding influence the risk of developing diabetes mellitus in children? A review of current evidence, J. Pediatr. (Rio. J) 90 (1) (2014) 7-15, https://doi.org/10.1016/j.jped.2013.02.024.

[5] C.E. Neville, M.C. McKinley, V.A. Holmes, D. Spence, J.V. Woodside, The relationship between breastfeeding and postpartum weight change-a systematic review and critical evaluation, Int. J. Obes. 38 (4) (2014) 577-590, https://doi.org/ 10.1038/ijo.2013.132.

[6] R. Chowdhury, B. Sinha, M.J. Sankar, et al., Breastfeeding and maternal health outcomes: a systematic review and meta-analysis, Acta Paediatr. Int. J. Paediatr. 104 (467) (2015) 93-113, https://doi.org/10.1111/apa.13102.

[7] C.M. Dieterich, J.P. Felice, E. O'Sullivan, K.M. Rasmussen, Breastfeeding and health outcomes for the mother-infant dyad, Pediatr. Clin. North Am. 60 (1) (2013) 31-48, https://doi.org/10.1016/j.pcl.2012.09.010.

[8] G.D.S. Buccini, R. Pérez-Escamilla, S.I. Venancio, Pacifier use and exclusive breastfeeding in Brazil, J. Hum. Lact. 32 (3) (2016) 52-60, https://doi.org/10. $1177 / 0890334415609611$.

[9] H. Boskabadi, S. Bagheri, Comparison between infants receiving traditional supplements (camel thorn, flix weed, and sugar water) and exclusively breast fed infants, Avicenna J. Phytomed. 5 (6) (2015) 479-484.

[10] H. Kronborg, E. Foverskov, M. Væth, R.D. Maimburg, The role of intention and selfefficacy on the association between breastfeeding of first and second child, a Danish cohort study, BMC Pregnancy Childbirth 18 (1) (2018) 454, https://doi.org/10. 1186/s12884-018-2086-5.

[11] I.S. Rocha, L.F. Lolli, M. Fujimaki, A. Gasparetto, N.B. da Rocha, Influence of maternal confidence on exclusive breastfeeding until six months of age: a systematic review, Influ da autoconfianca Matern sobre o aleitamento Matern Exclus aos seis meses idade uma revisao Sist 23 (11) (2018) 3609-3619, https://doi.org/10.1590/ 1413-812320182311.20132016.

[12] N. Maharlouei, A. Pourhaghighi, H. Raeisi Shahraki, D. Zohoori, Lankarani KB. Factors affecting exclusive breastfeeding, using adaptive LASSO regression, Int. J. Community based Nurs. Midwifery 6 (3) (2018) 260-271.
[13] P. Datta, T. Baker, T.W. Hale, Balancing the use of medications while maintaining breastfeeding, Clin. Perinatol. 46 (2) (2019) 367-382, https://doi.org/10.1016/j. clp.2019.02.007.

[14] E.E. Stultz, J.L. Stokes, M.L. Shaffer, I.M. Paul, C.M. Berlin, Extent of medication use in breastfeeding women, Breastfeed. Med. 2 (3) (2007) 145-151, https://doi.org/ $10.1089 / \mathrm{bfm} .2007 .0010$.

[15] P.O. Anderson, S.L. Pochop, A.S. Manoguerra, Adverse drug reactions in breastfed infants: less than imagined, Clin. Pediatr. (Phila.) 42 (4) (2003) 325-340, https:// doi.org/10.1177/000992280304200405.

[16] R. Pilvinienè, R. Mačiulaitis, R. Jankūnas, I. Milvidaitė, E. Markuniene, Breastfeeding and medications, Medicine 42 (12) (2006) 1035-1045.

[17] H. Rowe, T. Baker, T.W. Hale, Maternal medication, drug use, and breastfeeding, Pediatr. Clin. North Am. 60 (1) (2013) 275-294, https://doi.org/10.1016/j.pcl. 2012.10.009.

[18] N. Alianmoghaddam, S. Phibbs, C. Benn, I did a lot of googling": a qualitative study of exclusive breastfeeding support through social media, Women Birth 32 (2) (2019) 147-156, https://doi.org/10.1016/j.wombi.2018.05.008.

[19] S. Kemp, Digital in 2018: World'S Internet Users Pass the 4 Billion Mark. New York, (2018).

[20] A. Arnold, How Millennials Use Social Media to Become More Competent Parents. Forbes, (2018) https://www.forbes.com/sites/andrewarnold/\#7c7e96bc13a7.

[21] P. Lialiou, J. Mantas, Online information seeking behaviour by nurses and physicians: a cross-sectional study, Stud. Health Technol. Inform. 225 (2016) 33-37, https://doi.org/10.3233/978-1-61499-658-3-33.

[22] P. Lialiou, I. Pavlopoulou, J. Mantas, Health professionals' use of online information retrieval systems and online evidence, Stud. Health Technol. Inform. 228 (2016) 801-803.

[23] A. Eglash, Website reviews, Breastfeed. Med. 1 (2) (2006) 122-123, https://doi. org/10.1089/bfm.2006.1.122.

[24] S. Reece-Stremtan, M. Campos, L. Kokajko, Academy of breastfeeding medicine. ABM clinical protocol \#15: analgesia and anesthesia for the breastfeeding mother, revised 2017, Breastfeed. Med. 12 (9) (2017) 500-506, https://doi.org/10.1089/ bfm.2017.29054.srt.

[25] D. Clark, D. Nicholas, H.R. Jamali, Evaluating information seeking and use in the changing virtual world: the emerging role of google analytics, Learn. Publ. 27 (3) (2014) 185-194, https://doi.org/10.1087/20140304.

[26] R. Davanzo, L. Rubert, C. Oretti, Meta-variability of advice on drugs in the breastfeeding mother: the example of $\beta$-blockers, Arch. Dis. Child. Fetal Neonatal Ed. 93 (3) (2008) 249-250, https://doi.org/10.1136/adc.2007.135764.

[27] S. Colaceci, A. Giusti, E.M. Chapin, et al., The difficulties in antihypertensive drug prescription during lactation: Is the information consistent? Breastfeed. Med. 10 (10) (2015) 468-473, https://doi.org/10.1089/bfm.2015.0086.

[28] P.O. Anderson, LactMed update-an introduction, Breastfeed. Med. 11 (2) (2016) 54-55, https://doi.org/10.1089/bfm.2015.0193.

[29] M. Akus, M. Bartick, Lactation safety recommendations and reliability compared in 10 medication resources, Ann. Pharmacother. 41 (9) (2007) 1352-1360, https:// doi.org/10.1345/aph.1K052.

[30] J. Wang, T. Johnson, L. Sahin, et al., Evaluation of the safety of drugs and biological products used during lactation: workshop summary, Clin. Pharmacol. Ther. 101 (6) (2017) 736-744, https://doi.org/10.1002/cpt.676.

[31] J. Gilmour, A. Strong, H. Chan, S. Hanna, A. Huntington, Primary health-care nurses and internet health information-seeking: access, barriers and quality checks, Int. J. Nurs. Pract. 22 (1) (2016) 53-60, https://doi.org/10.1111/ijn.12361.

[32] M. Raminelli, R.H. Siomara, Medicamentos na amamentação: quais as evidências? Ciênc saúde coletiva 24 (2) (2019) 573-587, https://doi.org/10.1590/141381232018242.30052016.

[33] E. Wolgast, L. Lindh-Astrand, C. Lillecretuz, Women's perceptions of medication use during pregnancy and breastfeeding-a Swedish cross-sectional questionnaire study, Acta Obstet. Gynecol. Scand. 98 (7) (2019) 856-864, https://doi.org/10.1111/ aogs.13570.

[34] World Health Organization, World Health Statistics. France, (2009) https://www. who.int/gho/publications/world health statistics/EN WHS09_Full.pdf?ua $=1$.

[35] Ditrendia, Ditrendia - Informe Mobile 2018. Madrid (Spain), (2018) https:// ditrendia.es/informe-mobile-2018/.

[36] P.O. Anderson, Choosing medication alternatives during breastfeeding, avoiding alternative facts, Breastfeed. Med. 12 (6) (2017) 328-330, https://doi.org/10. 1089/bfm.2017.0077.

[37] S. Ito, Mother and child: medication use in pregnancy and lactation, Clin Pharmacol. Ther. 100 (1) (2016) 8-11, https://doi.org/10.1002/cpt.383.

[38] T. Zheng, D. Yao, W. Chen, H. Hu, C.O.L. Ung, J.E. Harnett, Healthcare providers' role regarding the safe and appropriate use of herbal products by breastfeeding mothers: a systematic literature review, Complement. Ther. Clin. Pract. 35 (2019) 131-147, https://doi.org/10.1016/j.ctcp.2019.01.011.

[39] M.B. Haastrup, A. Pottegård, P. Damkier, Alcohol and breastfeeding, Basic Clin. Pharmacol. Toxicol. 114 (2) (2014) 168-173, https://doi.org/10.1111/bcpt.12149.

[40] P.O. Anderson, Medication information sources for breastfeeding mothers, Breastfeed. Med. 12 (7) (2017) 396-397, https://doi.org/10.1089/bfm.2017.0110. 